\title{
ON A PARAMETRIC MORE ACCURATE HILBERT-TYPE INEQUALITY
}

\author{
QIANG CHEN AND BICHENG YANG*
}

Abstract. By the use of the weight functions, the idea of introducing parameters and HermiteHadamard's inequality, a more accurate discrete Hilbert-type inequality with the general homogeneous kernel and the equivalent form are given. The equivalent statements of the best possible constant factor related to some parameters, the operator expressions and some particular cases are considered.

Mathematics subject classification (2010): 26D15.

Keywords and phrases: Weight function, Hilbert-type inequality, equivalent statement, Hermite-Hadamard's inequality, operator expression.

\section{REFERENCES}

[1] G. H. Hardy, J. E. Littlewood and G. Pólya, Inequalities, Cambridge University Press, Cambridge, 1934.

[2] B. C. YANG, The norm of operator and Hilbert-type inequalities, Science Press, Beijing, China, 2009.

[3] B. C. YANG, Hilbert-type integral inequalities, Bentham Science Publishers Ltd., The United Arab Emirates, 2009.

[4] B. C. YANG, On the norm of an integral operator and applications, J. Math. Anal. Appl., 2006, 321, $182-192$.

[5] J. S. XU, Hardy-Hilbert's inequalities with two parameters, Advances in Mathematics, 2007, 36(2), $63-76$.

[6] B. C. YANG, On the norm of a Hilbert's type linear operator and applications, J. Math. Anal. Appl., 2007, 325, 529-541.

[7] Z. T. XIE, Z. ZENG AND Y. F. SUN, A new Hilbert-type inequality with the homogeneous kernel of degree -2, Advances and Applications in Mathematical Sciences, 2013, 12(7), 391-401.

[8] Z. ZENG, K. RAJA RAma GANDhI AND Z. T. XIE, A new Hilbert-type inequality with the homogeneous kernel of degree -2 and with the integral, Bulletin of Mathematical Sciences and Applications, 2014, 3(1),11-20.

[9] D. M. XIN, A Hilbert-type integral inequality with the homogeneous kernel of zero degree, Mathematical Theory and Applications, 2010, 30(2), 70-74.

[10] L. E. AZAR, The connection between Hilbert and Hardy inequalities, Journal of Inequalities and Applications (2013), 2013: 452.

[11] V. AdiYASUREN, T. BATBOLD AND M. KRnić, Hilbert-type inequalities involving differential operators, the best constants and applications, Math. Inequal. Appl. 2015, 18(1), 111-124.

[12] M. TH. RASSIAS AND B. C. YANG, On half-discrete Hilbert's inequality, Applied Mathematics and Computation, 2013, 220, 75-93.

[13] B. C. YANG AND M. KRNIĆ, A half-discrete Hilbert-type inequality with a general homogeneous kernel of degree 0, Journal of Mathematical Inequalities, 2012, 6(3), 401-417.

[14] M. TH. RASSIAS AND B. C. YANG, A multidimensional half-discrete Hilbert-type inequality and the Riemann zeta function, Applied Mathematics and Computation, 2013, 225, 263-277.

[15] M. TH. Rassias, B. C. YANG, On a multidimensional half-discrete Hilbert-type inequality related to the hyperbolic cotangent function, Applied Mathematics and Computation, 2013, 242, 800-813.

[16] Z. X. HUANG AND B. C. YANG, On a half-discrete Hilbert-type inequality similar to Mulholland's inequality, Journal of Inequalities and Applications (2013), 2013: 290. 
[17] B. C. Yang And L. Debnath, Half-discrete Hilbert-type inequalities, World Scientific Publishing, Singapore, 2014.

[18] Y. Hong Y AND Y. M. Wen, A necessary and sufficient condition of that Hilbert type series inequality with homogeneous kernel has the best constant factor, Annals Mathematica, 2016, 37A(3), 329-336.

[19] Y. Hong, On the structure character of Hilbert's type integral inequality with homogeneous kernel and applications, Journal of Jilin University (Science Edition), 2017, 55(2), 189-194.

[20] Y. Hong, Q. L. HuAnG, B. C. YANG AND J. Q. LiAO, The necessary and sufficient conditions for the existence of a kind of Hilbert-type multiple integral inequality with the non-homogeneous kernel and its applications, Journal of Inequalities and Applications (2017), 2017:316.

[21] D. M. XIN, B. C. YANG AND A. Z. WANG, Equivalent property of a Hilbert-type integral inequality related to the beta function in the whole plane, Journal of Function Spaces, Volume 2018, Article ID2691816, 8 pages.

[22] Y. Hong, B. He AND B. C. YANG, Necessary and sufficient conditions for the validity of Hilbert type integral inequalities with a class of quasi-homogeneous kernels and its application in operator theory, Journal of Mathematics Inequalities, 2018, 12(3), 777-788.

[23] Z. X. HUANG AND B. C. YANG, Equivalent property of a half-discrete Hilbert's inequality with parameters, Journal of Inequalities and Applications (2018), 2018:333.

[24] J. C. KuAng, Applied inequalities, Shangdong Science and Technology Press, Jinan, China, 2004.

[25] J. C. KUANG, Real analysis and functional analysis (continuation) (second volume), Higher Education Press, Beijing, China, 2015.

[26] B. C. YANG, On a more accurate multidimensional Hilbert-type inequality with parameters, Mathematical Inequalities and Applications, 2015, 18(2), 429-441. 